\title{
The Fluorescence of $\mathrm{Pr}^{3+}$ in Zinc Lithium Bismuth Borate Glasses with Large Stimulated Emission Cross Section
}

\author{
Beena Bhatia, S. L. Meena \\ Ceramic Laboratory, Department of Physics, Jai Narain Vyas University, Jodhpur, India \\ Email: shankardiya7@rediffmail.com
}

Received 20 December 2015; accepted 2 April 2016; published 5 April 2016

Copyright (C) 2016 by authors and Scientific Research Publishing Inc.

This work is licensed under the Creative Commons Attribution International License (CC BY).

http://creativecommons.org/licenses/by/4.0/

(c) (i) Open Access

\begin{abstract}
Glass sample of Zinc Lithium Bismuth Borate $(25-x) \mathrm{Bi}_{2} \mathrm{O}_{3}: 20 \mathrm{Li}_{2} 0: 20 \mathrm{ZnO}: 35 \mathrm{~B}_{2} \mathrm{O}_{3}: \mathrm{Pr}_{6} \mathrm{O}_{11},(\mathrm{where} \mathrm{x}$ $=1,1.5$ and $2 \mathrm{~mol} \%$ ) has been prepared by melt-quenching technique. The amorphous nature of the prepared glass samples was confirmed by X-ray diffraction. The absorption spectra of three Pr $^{3+}$ doped zinc lithium bismuth borate glasses have been recorded at room temperature. The observed optical spectra are discussed in terms of energy states and the intensity of the transitions. The various interaction parameters like Slater-Condon, Lande, bonding and Racah parameters have been computed. Judd-Ofelt intensity parameters and laser parameters have also been calculated. The stimulated emission cross section $\left(\sigma_{p}\right)$ for the transition $\left({ }^{3} P_{0} \rightarrow{ }^{3} F_{2}\right)$ is found to be in the range $3.12-10.43 \times 10^{-20} \mathrm{~cm}^{2}$. The $\sigma_{p}$ values are comparatively large suggesting the possible utilization of these materials in laser applications.
\end{abstract}

\section{Keywords}

Zinc Lithium Bismuth Borate Glasses, Energy Interaction Parameters, Optical Properties, Judd-Ofelt Analysis

\section{Introduction}

Rare earth doped solid state materials have become an important class of solids, attracting much attention among researches as is evident from the abundance of studies that can be found in the literature. A substantial amount of work has been done on the lasing characteristics of rare earth doped solid state materials [1] [2].

Glasses are good host for rare earth ions, easy to make and at the same time they can be tailored for specific applications [3]-[5]. Most of the glasses developed for laser action give suitable laser transition in NIR region

How to cite this paper: Bhatia, B. and Meena, S.L. (2016) The Fluorescence of $\mathrm{Pr}^{3+}$ in Zinc Lithium Bismuth Borate Glasses with Large Stimulated Emission Cross Section. New Journal of Glass and Ceramics, 6, 9-17.

http://dx.doi.org/10.4236/njgc.2016.62002 
whereas $\mathrm{Pr}^{3+}$ doped glasses lase in visible region. Praseodymium doped glasses have wide application such as UV-VIS-NIR lasers, up converters, optical fiber amplifier etc. [6]-[8].

Since the spectroscopic properties of rare earth ions are strongly affected by glass composition the host glass composition were tailored with spectroscopic features of $\mathrm{Pr}^{3+}$ ion suitable for efficient laser performance.

Some spectral studies have been reported for $\mathrm{Pr}^{3+}$ doped borate and phosphate glasses by Weber [9] [10], Riesfeld [11] [12], Lakshman [13] and Tandon et al. [14]-[16]. Recently, such studies have been reported on $\mathrm{Pr}^{3+}$ doped bismuth borate glasses by our group [17].

In this communication, these studies have been extended by adding higher mol\% of $\mathrm{Bi}_{2} \mathrm{O}_{3}$ in $\mathrm{Pr}^{3+}$ doped zinc lithium bismuth borate glasses.

Large stimulated emission cross section is one of the most important parameters required for the design of high peak power solid state lasers. Thus, the variation of $\sigma_{p}$ with glass composition (e.g., borate, phosphates, silicates, etc.) has become the subject of intensive study because it is necessary to maximize $\sigma_{p}$ to achieve the best performance from an amplifier or laser system [18].

In the present work, the effect of bismuth borate matrix on the fluorescence properties of $\mathrm{Pr}^{3+}$ is investigated. The compositional dependence of the stimulated emission cross section of the $\left({ }^{3} \mathrm{P}_{0} \rightarrow{ }^{3} \mathrm{~F}_{2}\right)$ transition of $\operatorname{Pr}^{3+}$ is discussed. A comparative study of predicted laser action in borate, phosphate and bismuth borate glasses doped with $\mathrm{Pr}^{3+}$ ions have also been discussed. The addition of higher mol\% of $\mathrm{Bi}_{2} \mathrm{O}_{3}$ in borate glasses enhances the value of stimulated emission cross section.

\section{Experimental Techniques}

\section{Preparation of Glasses}

The following $\mathrm{Pr}^{3+}$ doped bismuth borate glass samples (25- $\mathrm{x}$ ) $\mathrm{Bi}_{2} \mathrm{O}_{3}: 20 \mathrm{Li}_{2} \mathrm{O}: 20 \mathrm{ZnO}: 35 \mathrm{~B}_{2} \mathrm{O}_{3}: x \mathrm{Pr}_{6} \mathrm{O}_{11}$ (where $x=$ $1,1.5,2$ ) have been prepared by melt-quenching method. Analytical reagent grade chemical used in the present study consist of $\mathrm{Bi}_{2} \mathrm{O}_{3}, \mathrm{Li}_{2} \mathrm{O}, \mathrm{ZnO}$, and $\mathrm{B}_{2} \mathrm{O}_{3}$ and $\mathrm{Pr}_{6} \mathrm{O}_{11}$. They were thoroughly mixed by using an agate pestle mortar.

Then melted at $1050^{\circ} \mathrm{C}$ by an electrical muffle furnace for 2 hours. After complete melting, the melts were quickly poured in to a preheated stainless steel mould and annealed at temperature of $350^{\circ} \mathrm{C}$ for $2 \mathrm{~h}$ to remove thermal strains and stresses. Every time fine powder of cerium oxide was used for polishing the samples. The glass samples so prepared were of good optical quality and were transparent. The chemical compositions of the glasses with the name of samples are summarized in Table 1.

\section{XRD Study}

Figure 1 represents the XRD pattern of the sample which shows no sharp Bragg's peak, but only a broad diffuse hump around low angle region. This is the clear indication of amorphous nature within the resolution limit of XRD instrument.

The amorphous nature of all samples was confirmed by the absence of Bragg's peak in X-ray diffraction pattern (Figure 1).

\section{Theory}

\subsection{Energy Interaction Parameters}

The energy $E_{j}$ can be expressed in terms of interaction parameters-(Slater-Condon) $F_{k}$, and $\xi_{4 f}$ (Lande) by Taylor

Table 1. Chemical composition of the glasses.

\begin{tabular}{cc}
\hline Sample & Glass composition (mol\%) \\
\hline ZnLiBiB (UD) & $25 \mathrm{Bi}_{2} \mathrm{O}_{3}: 20 \mathrm{Li}_{2} \mathrm{O}: 20 Z n O: 35 \mathrm{~B}_{2} \mathrm{O}_{3}$ \\
ZnLiBiB (PR1) & $24 \mathrm{Bi}_{2} \mathrm{O}_{3}: 20 \mathrm{Li}_{2} \mathrm{O}: 20 Z \mathrm{ZnO}: 35 \mathrm{~B}_{2} \mathrm{O}_{3}: 1 \mathrm{Pr}_{6} \mathrm{O}_{11}$ \\
ZnLiBiB (PR1.5) & $23.5 \mathrm{Bi}_{2} \mathrm{O}_{3}: 20 \mathrm{Li}_{2} \mathrm{O}: 20 \mathrm{ZnO}: 35 \mathrm{~B}_{2} \mathrm{O}_{3}: 1.5 \mathrm{Pr}_{6} \mathrm{O}_{11}$ \\
ZnLiBiB (PR2) & $23 \mathrm{Bi}_{2} \mathrm{O}_{3}: 20 \mathrm{Li}_{2} \mathrm{O}: 20 Z n O: 35 \mathrm{~B}_{2} \mathrm{O}_{3}: 2 \mathrm{Pr}_{6} \mathrm{O}_{11}$ \\
\hline
\end{tabular}

ZnLiBiB (UD)—Represents undoped Zinc Lithium Bismuth Borate glass specimens ZnLiBiB (PR)—Represents $\operatorname{Pr}^{3+}$ doped Zinc Lithium Bismuth Borate glass specimens. 


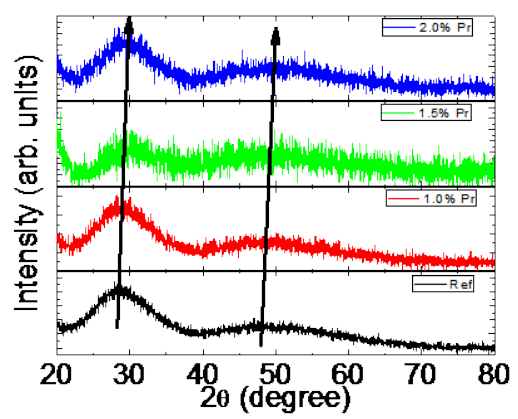

Figure 1. X-ray diffraction pattern of $\mathrm{Bi}_{2} \mathrm{O}_{3}: \mathrm{Li}_{2} \mathrm{O}: \mathrm{ZnO}: \mathrm{B}_{2} \mathrm{O}_{3}: \mathrm{Pr}_{6} \mathrm{O}_{11}$.

series expansion for a small variation of energies $\Delta E_{j}$. In the first order approximation, the energy $E_{j}$ of the $j^{\text {th }}$ level is given by [19] [20].

$$
E_{j}\left(F_{k}, \zeta_{4 f}\right)=E_{o j}\left(F^{0} k, \xi_{4 f}\right)+\sum_{k=2,4,6} \frac{\partial E_{j}}{\partial F_{k}} \Delta F_{k}+\frac{\partial E_{j}}{\partial \xi_{4 f}} \Delta \xi_{4 f}, k=2,4,6
$$

where, $E_{o j}$ is the zero order energy of $j^{\text {th }}$ level and $\Delta F_{k}$ and $\Delta \xi_{4 f}$ are the small changes in the corresponding parameters and these values have been calculated by partial regression method.

The value of $F_{k}$ and $\xi_{4 f}$ are then evaluated using equations.

$$
\begin{aligned}
& F_{k}=F_{k}^{0}+\Delta F_{k}^{0} \\
& \xi_{4 f}=\xi_{4 f}^{0}+\xi_{4 f}
\end{aligned}
$$

where, $F_{k}^{0}$ and $\xi_{4 f}^{0}$ are zero order values of the parameters $F_{k}$ and $\xi_{4 f}$, respectively.

The Racah parameters $E^{k}(k=1,2,3)$ can be expressed as linear combination of $F_{k}(k=2,4,6)$ given by

$$
\begin{gathered}
E^{1}=\left(70 F_{2}+231 F_{4}+2002 F_{6}\right) / 9 \\
E^{2}=\left(F_{2}-3 F_{4}+7 F_{6}\right) / 9 \\
E^{3}=\left(5 F_{2}+6 F_{4}-91 F_{6}\right) / 3
\end{gathered}
$$

\subsection{Oscillator Strength}

The intensity of spectral lines are expressed in terms of oscillator strengths using the relation [21].

$$
f_{\text {expt }}=4.318 \times 10^{-9} \int \varepsilon(v) \mathrm{d} v
$$

where, $\varepsilon(v)$ is molar absorption coefficient at a given energy $v\left(\mathrm{~cm}^{-1}\right)$, to be evaluated from Beer-Lambert law.

Under Gaussian Approximation, using Beer-Lambert law, the observed oscillator strengths of the absorption bands have been experimentally calculated, using the modified relation [22].

$$
P_{m}=4.6 \times 10^{-9} \times \frac{1}{c l} \log \frac{I_{0}}{I} \times \Delta v_{1 / 2}
$$

where $c$ is the molar concentration of the absorbing ion per unit volume, $I$ is the optical path length, $\log I_{0} / I$ is absorbtivity or optical density and $\Delta v_{1 / 2}$ is half band width.

\subsection{Judd-Ofelt Intensity Parameters}

According to Judd [23] and Ofelt [24] theory, independently derived expression for the oscillator strength of the induced forced electric dipole transitions between an initial $J$ manifold $\left|4 f^{N}(S, L) J\right\rangle$ level and the terminal $J^{\prime}$ manifold $\left|4 f^{N}\left(S^{\prime}, L^{\prime}\right) J^{\prime}\right\rangle$ is given by: 


$$
\frac{8 \Pi^{2} m c \bar{v}}{3 h(2 J+1)} \frac{1}{n}\left[\frac{\left(n^{2}+2\right)^{2}}{9}\right] \times S\left(J, J^{\prime}\right)
$$

where, the line strength $S\left(J, J^{\prime}\right)$ is given by the equation

$$
S\left(J, J^{\prime}\right)=e^{2} \sum_{\lambda=2,4,6} \Omega_{\lambda}<4 f^{N}(S, L) J\left\|U^{(\lambda)}\right\| 4 f^{N}\left(S^{\prime}, L^{\prime}\right) J^{\prime}>2, \lambda=2,4,6
$$

In the above equation $m$ is the mass of an electron, $c$ is the velocity of light, $v$ is the wave number of the transition, $h$ is Planck's constant, $\mathrm{n}$ is the refractive index, $J$ and $J^{\prime}$ are the total angular momentum of the initial and final level respectively, $\Omega_{\lambda}(\lambda=2$, 4 and 6) are known as Judd-Ofelt intensity parameters which contain the effect of the odd-symmetry crystal field terms, radial integrals and energy denominators. $\left\|U^{(\lambda)}\right\|^{2}$ are the matrix elements of the doubly reduced unit tensor operator calculated in intermediate coupling approximation. $\Omega_{\lambda}$ parameter can be obtained from least square fitting method [25]. The matrix element $\left\|U^{(\lambda)}\right\|^{2}$ that are insensitive to the environment of rare earth ions were taken from the literature [26].

\subsection{Radiative Properties}

The $\Omega_{\lambda}$ parameters obtained using the absorption spectral results have been used to predict radiative properties such as spontaneous emission probability $(A)$ and radiative life time $\left(\tau_{R}\right)$, and laser parameters like fluorescence branching ratio $\left(\beta_{R}\right)$ and stimulated emission cross section $\left(\sigma_{p}\right)$.

The spontaneous emission probability from initial manifold $\left|4 f^{N}\left(S^{\prime}, L^{\prime}\right) J^{\prime}\right\rangle$ to a final manifold $\left|4 f^{N}(S, L) J\right\rangle$ is given by:

$$
A\left[\left(S^{\prime}, L^{\prime}\right) J^{\prime} ;(S, L) J\right]=\frac{64 \pi^{2} v^{3}}{3 h\left(2 J^{\prime}+1\right)} \frac{n\left(n^{2}+2\right)^{2}}{9} \times S\left(J^{\prime}, \bar{J}\right)
$$

where, $S\left(J^{\prime}, J\right)=e^{2}\left[\Omega_{2}\left\|U^{(2)}\right\|+\Omega_{4}\left\|U^{(4)}\right\|^{2}+\Omega_{6}\left\|U^{(6)}\right\|^{2}\right]$

The fluorescence branching ratio for the transitions originating from a specific initial manifold $\left|4 f^{N}\left(S^{\prime}, L^{\prime}\right) J^{\prime}\right\rangle$ to a final many fold $\left|4 f^{N}(S, L) J\right\rangle$ is given by

$$
\beta\left[\left(S^{\prime}, L^{\prime}\right) J^{\prime} ;(S, L) J\right]=\frac{A\left[\left(S^{\prime} L\right)\right]}{\sum_{S L J} A\left[\left(S^{\prime} L^{\prime}\right) J^{\prime}(\bar{S} L)\right]}
$$

where, the sum is over all terminal manifolds.

The radiative life time is given by

$$
\tau_{\text {rad }}=\sum_{S L J} A\left[\left(S^{\prime}, L^{\prime}\right) J^{\prime} ;(\bar{S}, L)\right]=A_{\text {Total }}^{-1}
$$

where, the sum is over all possible terminal manifolds. The stimulated emission cross -section for a transition from an initial manifold $\left|4 f^{N}\left(S^{\prime}, L^{\prime}\right) J^{\prime}\right\rangle$ to a final manifold

$\left|4 f^{N}(S, L) J\right\rangle$ is expressed as

$$
\sigma_{p}\left(\lambda_{p}\right)=\left[\frac{\lambda_{p}^{4}}{8 \pi c n^{2} \Delta \lambda_{\text {eff }}}\right] \times A\left[\left(S^{\prime}, L^{\prime}\right) J^{\prime} ;(\bar{S}, \bar{L}) \bar{J}\right]
$$

where, $\lambda_{p}$ the peak fluorescence wavelength of the emission band and $\Delta \lambda_{\text {eff }}$ is the effective fluorescence line width.

\subsection{Nephelauxetic Ratio ( $\beta^{\prime}$ ) and Bonding Parameter $\left(b^{1 / 2}\right)$}

The nature of the R-O bond is known by the Nephelauxetic Ratio $\left(\beta^{\prime}\right)$ and Bonding Parameter $\left(b^{1 / 2}\right)$, which 
are computed by using following formulae [27]. The Nephelauxetic Ratio is given by

$$
\beta^{\prime}=\frac{v_{g}}{v_{a}}
$$

where, $v_{a}$ and $v_{g}$ refer to the energies of the corresponding transition in the glass and free ion, respectively. The values of bonding parameter $b^{1 / 2}$ are given by

$$
b^{1 / 2}=\frac{1-\bar{\beta}}{\bar{\beta}}
$$

where $\bar{\beta}$ is the average value of $\beta^{\prime}$.

\section{Results and Discussion}

\subsection{Optical Properties}

\section{Absorption Spectrum}

The absorption spectra of these glasses were recorded between wavelengths range 400 - $900 \mathrm{~nm}$ with a Spctro Scan 80D/80DV Spectrophotometer and 900 - 2250 nm with a Perkin-Elmer Lambda 750 UV/VIS/NIR Spectrophotometer at room temperature.

The absorption spectra of $\operatorname{Pr}^{3+}$ doped $\mathrm{ZnLiBiB}$ glass specimens have been represented in Figure 2 in terms of relative absorption $\left(I / I_{0}\right)$ versus wavelength $(\mathrm{nm})$, where $I$ and $I_{0}$ are intensities of the radiation transmitted through doped specimens and undoped specimens of equal thickness. Eight absorption bands UV-VIS and NIR region have been observed from the ground state ${ }^{3} \mathrm{H}_{4}$ to excited states ${ }^{3} \mathrm{P}_{2},{ }^{3} \mathrm{P}_{1},{ }^{3} \mathrm{P}_{0},{ }^{1} \mathrm{D}_{2},{ }^{1} \mathrm{G}_{4},{ }^{3} \mathrm{~F}_{4},{ }^{3} \mathrm{~F}_{3}$ and ${ }^{3} \mathrm{~F}_{2}$ for $\mathrm{Pr}^{3+}$ doped $\mathrm{ZnLiBiB}$ glasses.

The optical absorption bands around the ${ }^{3} \mathrm{P}_{2}(446 \mathrm{~nm}),{ }^{3} \mathrm{P}_{1}(469 \mathrm{~nm}),{ }^{3} \mathrm{P}_{0}(485 \mathrm{~nm}),{ }^{1} \mathrm{D}_{2}(592 \mathrm{~nm}),{ }^{1} \mathrm{G}_{4}(1010$ $\mathrm{nm}),{ }^{3} \mathrm{~F}_{4}(1442 \mathrm{~nm}),{ }^{3} \mathrm{~F}_{3}(1527 \mathrm{~nm})$ and ${ }^{3} \mathrm{~F}_{2}(1936 \mathrm{~nm})$, are assigned from the ground state, ${ }^{3} \mathrm{H}_{4}$, Assignment have been made by published article [28]. From the absorption spectra, experimental oscillator strengths have been calculated for all the absorption bands.

The experimental and calculated oscillator strengths for $\mathrm{Pr}^{3+}$ ions in zinc lithium bismuth borate glasses are given in Table 2. Racah parameters $\left(E^{k}\right)$ have been deduced from $F_{k}$ parameters [29] (Table 3). The ratio of Racah parameters $E^{1} / E^{3}$ and $E^{2} / E^{3}$ are about 10 and 0.05 respectively. Which are almost equal to the hydrogenic ratio [30]. This implies that $\mathrm{Pr}^{3+}$ ions at different doping concentrations are subjected.

Further Judd-Ofelt intensity parameters $\Omega_{\lambda}(\lambda=2,4$ and 6) were calculated by using the fitting approximation of the experimental oscillator strengths to the calculated oscillator strengths with respect to their electric dipole contributions. In the present case the three $\Omega_{\lambda}$ parameters follow the trend $\Omega_{2}<\Omega_{4}<\Omega_{6}$. The spectroscopic quality factor $\left(\Omega_{4} / \Omega_{6}\right)$ related with the rigidity of the glass system has been found to lie between 0.4 and 0.7 in the

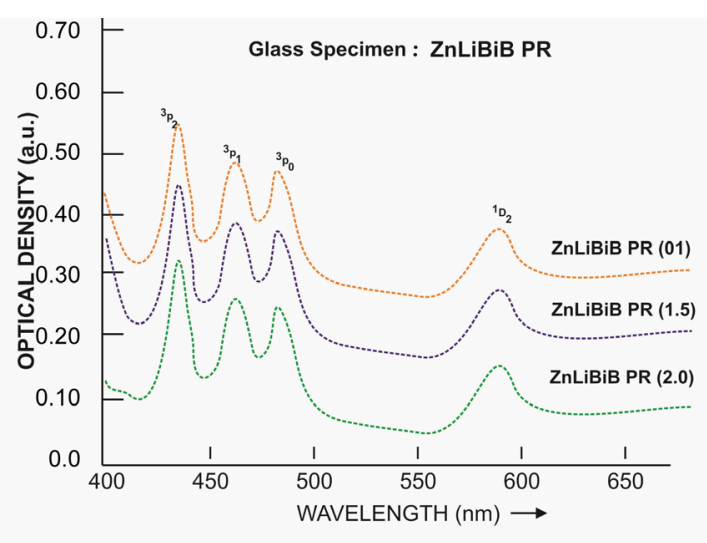

(a)

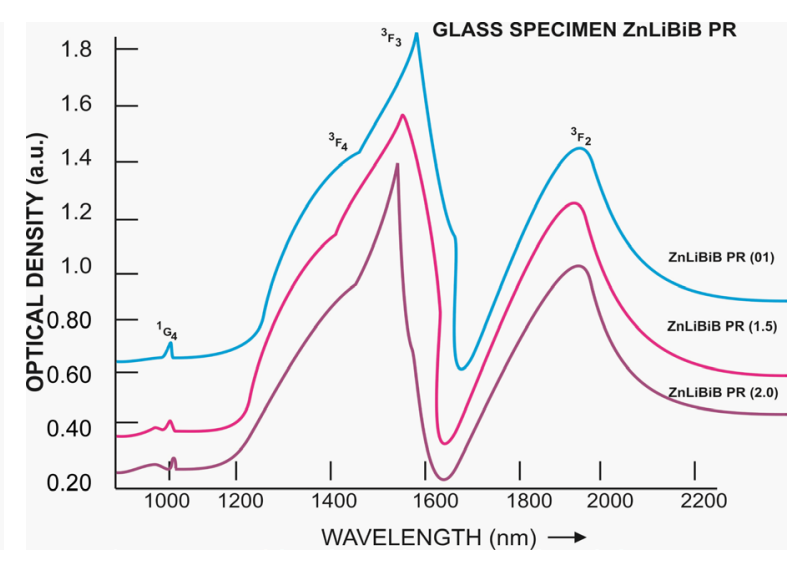

(b)

Figure 2. (a) Absorption spectrum of $\mathrm{ZnLiBiB}$ glasses doped with $\mathrm{Pr}^{3+}$ inUV-VIS region; (b) Absorption spectrum of $\mathrm{ZnLiBiB}$ glasses doped with $\mathrm{Pr}^{3+}$ in NIR region. 
Table 2. Measured and calculated oscillator strength $\left(P_{m} \times 10^{+6}\right)$ of $\operatorname{Pr}^{3+}$ ions in $\mathrm{ZnLiBiB}$ glasses.

\begin{tabular}{|c|c|c|c|c|c|c|}
\hline $\begin{array}{c}\text { Energy level from } \\
{ }^{3} \mathbf{H}_{4}\end{array}$ & $\begin{array}{l}\text { Glass ZnLiBiB } \\
\text { (PR01) }\end{array}$ & & $\begin{array}{c}\text { Glass ZnLiBiB } \\
\text { (PR1.5) }\end{array}$ & & $\begin{array}{l}\text { Glass ZnLiBiB } \\
\text { (PR02) }\end{array}$ & \\
\hline & $\mathrm{P}_{\exp }$ & $\mathrm{P}_{\text {cal. }}$. & $\mathrm{P}_{\text {exp }}$ & $\mathrm{P}_{\text {cal. }}$. & $\mathrm{P}_{\exp }$ & $P_{\text {cal. }}$. \\
\hline${ }^{3} \mathrm{~F}_{2}$ & 4.121 & 3.556 & 3.23 & 2.792 & 2.12 & 1.838 \\
\hline${ }^{3} \mathrm{~F}_{3}$ & 7.82 & 6.916 & 6.126 & 5.355 & 5.125 & 4.440 \\
\hline${ }^{3} \mathrm{~F}_{4}$ & 4.435 & 4.315 & 3.226 & 3.317 & 2.112 & 2.682 \\
\hline${ }^{1} \mathrm{G}_{4}$ & 0.482 & 0.362 & 0.360 & 0.279 & 0.240 & 0.229 \\
\hline${ }^{1} \mathrm{D}_{2}$ & 3.241 & 1.234 & 2.12 & 0.952 & 1.116 & 0.783 \\
\hline${ }^{3} \mathrm{P}_{0}$ & 4.321 & 1.869 & 3.226 & 1.510 & 2.154 & 1.512 \\
\hline${ }^{3} \mathrm{P}_{1}$ & 4.128 & 3.183 & 3.125 & 2.541 & 2.106 & 2.406 \\
\hline${ }^{3} \mathrm{P}_{2}$ & 11.12 & 4.116 & 10.107 & 3.175 & 9.816 & 2.623 \\
\hline r.m.s. deviation & \pm 2.776 & & \pm 2.586 & & \pm 2.579 & \\
\hline
\end{tabular}

Table 3. Computed values of Slater-Condon, Lande, Racah, nephelauexetic ratio and bonding parameter for $\operatorname{Pr}^{3+}$ doped ZnLiBiB glass specimens.

\begin{tabular}{ccccc}
\hline Parameter & Free ion & ZnLiBiB PR01 & ZnLiBiB PR1.5 & ZnLiBiB PR02 \\
\hline$F_{2}\left(\mathrm{~cm}^{-1}\right)$ & 322.09 & 299.62 & 299.21 & 298.83 \\
$F_{4}\left(\mathrm{~cm}^{-1}\right)$ & 44.46 & 44.36 & 44.35 & 44.28 \\
$F_{6}\left(\mathrm{~cm}^{-1}\right)$ & 4.867 & 4.427 & 4.407 & 4.397 \\
$\xi_{4 f}\left(\mathrm{~cm}^{-1}\right)$ & 741.00 & 856.74 & 856.80 & 858.36 \\
$E^{1}\left(\mathrm{~cm}^{-1}\right)$ & 4728.92 & 4453.71 & 4445.82 & 4438.84 \\
$E^{2}\left(\mathrm{~cm}^{-1}\right)$ & 24.75 & 21.95 & 21.89 & 21.86 \\
$E^{3}\left(\mathrm{~cm}^{-1}\right)$ & 478.10 & 453.80 & 453.70 & 453.23 \\
$F_{4} / F_{2}$ & 0.13805 & 0.14805 & 0.14822 & 0.14818 \\
$F_{6} / F_{2}$ & 0.01511 & 0.01478 & 0.01473 & 0.01471 \\
$E^{1} / E^{3}$ & 9.8911 & 9.8143 & 9.7990 & 9.7938 \\
$E^{2} / E^{3}$ & 0.0518 & 0.0484 & 0.0483 & 0.0482 \\
$\beta^{\prime}$ & & 0.9302 & 0.9290 & 0.9278 \\
$b^{1 / 2}$ & & 0.1868 & 0.1884 & 0.1900
\end{tabular}

present glasses. The values of Judd-Ofelt intensity parameters are given in Table 4.

A comparison of calculated $\sigma$ values for bismuth borate glasses with those reported [31] for borate, silicate, fluoroberyllate, phosphate and tellurite glasses (Figure 3) shows that bismuth borate glasses are best and tellurite glasses the next best. However, tellurite glasses have low transmission in the desired region (NIR) due to high value of refractive index.

Computed values of Slater-Condon, Lande, Racah, nephelauexetic ratio and bonding parameter for $\operatorname{Pr}^{3+}$ doped ZnLiBiB glass specimens are given in Table 3.

\subsection{Fluorescence Spectrum}

The fluorescence spectrum of $\mathrm{Pr}^{3+}$ doped in zinc lithium bismuth borate glass is shown in Figure 4. There are four broad bands $\left({ }^{3} \mathrm{P}_{0} \rightarrow{ }^{3} \mathrm{H}_{4}\right),\left({ }^{3} \mathrm{P}_{0} \rightarrow{ }^{3} \mathrm{H}_{5}\right),\left({ }^{3} \mathrm{P}_{0} \rightarrow{ }^{3} \mathrm{H}_{6}\right)$ and $\left({ }^{3} \mathrm{P}_{0} \rightarrow{ }^{3} \mathrm{~F}_{2}\right)$, respectively for glass specimens. Out of four emission transition observed from ${ }^{3} \mathrm{P}_{0}$ level, only three $\left({ }^{3} \mathrm{P}_{0} \rightarrow{ }^{3} \mathrm{H}_{4},{ }^{3} \mathrm{H}_{6}\right.$ and $\left.{ }^{3} \mathrm{~F}_{2}\right)$ are included in the fit. The transition ${ }^{3} \mathrm{P}_{0} \rightarrow{ }^{3} \mathrm{H}_{5}$ is excluded since the matrix elements for this transition are zero and the $\beta$ is too weak to measure. 


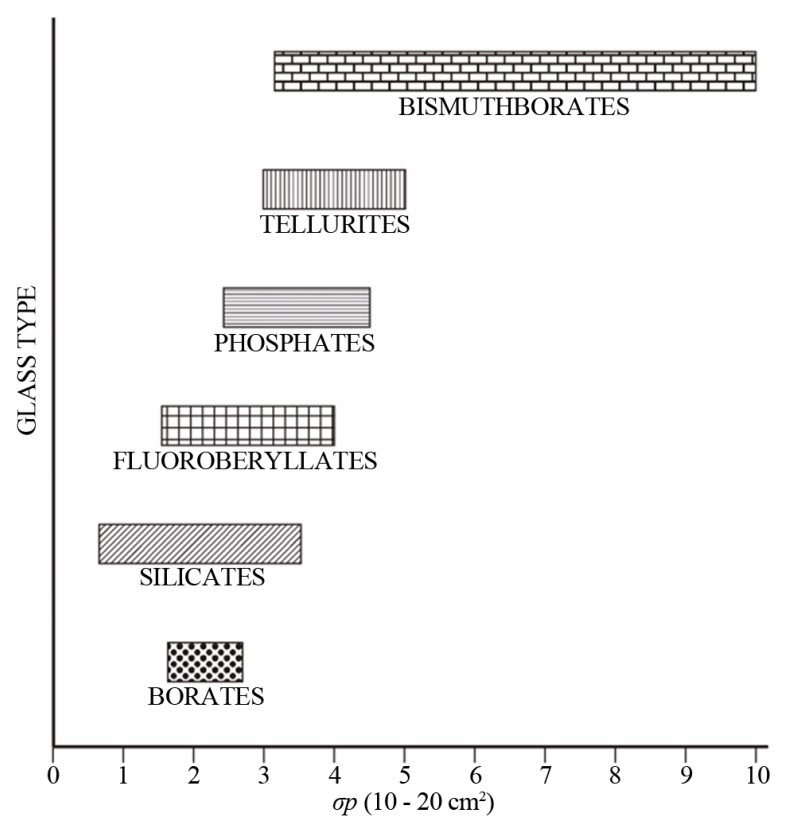

Figure 3. Range of stimulated emission cross-section for different $\operatorname{Pr}^{3+}$ doped glasses.

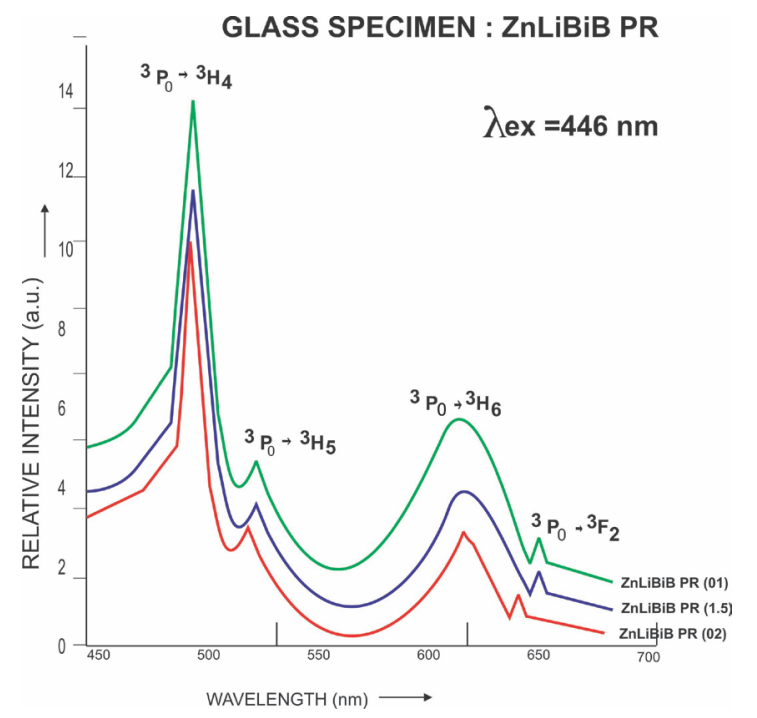

Figure 4. Fluorescence spectrum of $\mathrm{ZnLiBiB}$ glasses doped with $\mathrm{Pr}^{3+}$.

Table 4. Judd-Ofelt intensity parameters for $\mathrm{Pr}^{3+}$ doped $\mathrm{ZnLiBiB}$ glass specimens.

\begin{tabular}{ccccc}
\hline Glass Specimen & $\mathbf{\Omega}_{\mathbf{2}}\left(\mathbf{p m}^{\mathbf{2}}\right)$ & $\mathbf{\Omega}_{\mathbf{4}}\left(\mathbf{p m}^{\mathbf{2}}\right)$ & $\left.\mathbf{\Omega}_{\mathbf{6}} \mathbf{( p m}^{\mathbf{2}}\right)$ & $\Omega_{4} / \mathbf{\Omega}_{6}$ \\
\hline ZnLiBiB (PR01) & 1.90 & 2.41 & 5.58 & 0.432 \\
ZnLiBiB (PR1.5) & 1.48 & 1.94 & 4.27 & 0.454 \\
ZnLiBiB (PR02) & 0.549 & 1.95 & 3.47 & 0.763 \\
\hline
\end{tabular}

The value of stimulated emission cross-section $\left(\sigma_{p}\right)$ is found to be maximum for the transition $\left({ }^{3} \mathrm{P}_{0} \rightarrow{ }^{3} \mathrm{~F}_{2}\right)$ for glass ZnLiBiB PR 01, suggesting that glass ZnLiBiB PR01 is better compared to the other two glass systems (ZnLiBiB PR1.5 and ZnLiBiB PR02). The wavelengths of these bands along with their assignments are given in Table 5. 
Table 5. Emission peak wave lengths $\left(\lambda_{p}\right)$, radiative transition probability $\left(A_{\text {rad }}\right)$, branching ratio $\left(\beta_{R}\right)$, stimulated emission crosssection $\left(\sigma_{p}\right)$, andradiative life time $(\tau)$ for various transitions in $\operatorname{Pr}^{3+}$ doped $\mathrm{ZnLiBiB}$ glasses.

\begin{tabular}{|c|c|c|c|c|c|c|c|c|c|c|c|c|c|}
\hline \multirow{2}{*}{ Transition } & \multicolumn{5}{|c|}{ ZnLiBiB PR 01} & \multicolumn{4}{|c|}{ ZnLiBiB PR 1.5} & \multicolumn{4}{|c|}{ ZnLiBiB PR 02} \\
\hline & $\lambda_{p}(\mathrm{~nm})$ & $A_{\text {rad }}\left(\mathrm{s}^{-1}\right)$ & $\beta_{R}$ & $\begin{array}{c}\sigma_{p} \\
\left(10^{-20} \mathrm{~cm}^{2}\right)\end{array}$ & $\tau(\mu \mathrm{s})$ & $A_{\text {rad }}\left(\mathrm{s}^{-1}\right)$ & $\beta_{R}$ & $\begin{array}{c}\sigma_{p} \\
\left(10^{-20} \mathrm{~cm}^{2}\right)\end{array}$ & $\tau(\mu \mathrm{s})$ & $A_{\text {rad }}\left(\mathrm{s}^{-1}\right)$ & $\beta_{R}$ & $\begin{array}{c}\sigma_{p} \\
\left(10^{-20} \mathrm{~cm}^{2}\right)\end{array}$ & $\tau(\mu \mathrm{s})$ \\
\hline${ }^{3} \mathrm{P}_{0} \rightarrow{ }^{3} \mathrm{H}_{4}$ & 485 & 16584.29 & 0.4755 & 2.385 & 60.302 & 13483.39 & 0.4880 & 1.871 & 74.079 & 13499.6 & 0.6251 & 1.746 & 74.076 \\
\hline${ }^{3} \mathrm{P}_{0} \rightarrow{ }^{3} \mathrm{H}_{5}$ & 528 & - & - & - & - & - & - & - & - & - & - & - & - \\
\hline${ }^{3} \mathrm{P}_{0} \rightarrow{ }^{3} \mathrm{H}_{6}$ & 610 & 8575.56 & 0.2459 & 3.585 & 116.610 & 6566.73 & 0.2377 & 2.638 & 189.204 & 5285.30 & 0.2447 & 2.042 & 189.20 \\
\hline${ }^{3} \mathrm{P}_{0} \rightarrow{ }^{3} \mathrm{~F}_{2}$ & 643 & 9715.70 & 0.2786 & 10.434 & 102.93 & 7578.47 & 0.2743 & 8.29 & 355.736 & 2811.07 & 0.1302 & 3.12 & 355.74 \\
\hline
\end{tabular}

\section{Conclusion}

In the present study, the glass samples of composition (25-x) $\mathrm{Bi}_{2} \mathrm{O}_{3}: 20 \mathrm{Li}_{2} \mathrm{O}: 20 \mathrm{ZnO}: 35 \mathrm{~B}_{2} \mathrm{O}_{3}: x \mathrm{Pr}_{6} \mathrm{O}_{11}$ (where $x=$ $1,1.5,2 \mathrm{~mol} \%)$ have been prepared by melt-quenching method. The stimulated emission cross section $\left(\sigma_{p}\right)$ and branching ratio $\left(\beta_{R}\right)$ values are calculated for present glasses. It could be observed that glass ZnLiBiB (PR01) possessed better values when compared to the other two glass systems. The large stimulated emission cross section in bismuth borate glasses suggests the possibility of utilizing these systems as laser materials.

\section{Acknowledgements}

Our sincere thanks to Prof. R.J. Sengwa, Head Department of physics for providing chemicals. (Rare Earths) I.I.T. Jodhpur, Defence lab, Jodhpur, are hereby acknowledged for providing facilities for sample preparation, spectral and X-ray measurements. The authors wish to express heartiest gratitude to Prof. S.P. Tandon, Retired Prof. of physics, J.N.V. University, Jodhpur, Dr. M.P. Bhutra Retired Associate Professor of physics J.N.V. University, Jodhpur for valuable suggestions.

\section{References}

[1] Sharma, Y.K., Tandon, S.P. and Surana, S.S.L. (2000) Laser Action in Praseodymium Doped Zinc Chloride Borophosphate Glasses. Journal of Materials Science and Engineering B, 77, 167-171. http://dx.doi.org/10.1016/S0921-5107(00)00471-2

[2] Tandon, S.P., Sharma, Y.K., Bishnoi, N.B. and Tandon, K. (1997) Optical Studies on Rare Earth Lasing Materials. Journal of Defence Science, 47, 225-238. http://dx.doi.org/10.14429/dsj.47.4004

[3] Zhou, S., Jiang, N., Zhu, B., Yang, H., Ye, S., Laksminarayana, G., Hao, J. and Qiu, J. (2008) Multifunctional Bismuth-Doped Nanoporous Silica Glass: From Blue-Green, Orange, Red and White Light Sources to Ultra-Broadband Infrared Amplifiers. Advanced Functional Materials, 18, 1407-1413. http://dx.doi.org/10.1002/adfm.200701290

[4] Meng, X.G., Qiu, J.R., Peng, M.Y., Chen, D.P., Zhao, Q.Z., Jiang, X.W. and Zhu, C.S. (2005) Near Infrared Broadband Emission of Bismuth-Doped Aluminophosphate Glass. Optics Express, 13, 1628-1634. http://dx.doi.org/10.1364/OPEX.13.001628

[5] Wang, Y., Dai, S., Chen, F., Xu, T. and Nie, Q. (2009) Physical Properties and Optical Band Gap of New Tellurite Glasses within the $\mathrm{TeO}_{2}-\mathrm{Nb}_{2} \mathrm{O}_{5}-\mathrm{Bi}_{2} \mathrm{O}_{3}$ System. Materials Chemistry and Physics, 113, 407-411. http://dx.doi.org/10.1016/j.matchemphys.2008.07.117

[6] Lu, M.H. and Sturm, J.C. (2002) Optimization of External Coupling and Light Emission in Organiclight-Emitting Devices: Modeling and Experiment. Journal of Applied Physics, 91. http://dx.doi.org/10.1063/1.1425448

[7] Vijay Prakash, G. (2000) Absorption Spectral Studies of Rare Earth Ions $\left(\mathrm{Pr}^{3+}, \mathrm{Nd}^{3+}, \mathrm{Sm}^{3+}, \mathrm{Dy}^{3+}, \mathrm{Ho}^{3+}\right.$ and $\mathrm{Er}^{3+}$ ) Doped in NASICON Type Phosphate Glass, $\mathrm{Na}_{4} \mathrm{AlZnP}_{3} \mathrm{O}_{12}$. Journal of Materials Letters, 46, 15-20.

[8] Rai, V.K., de S. Menezes, L. and de Araújo, C.B. (2007) Spectroscopy, Energy Transfer and Frequency Upconversion in $\mathrm{Tm}^{3+}$-Doped $\mathrm{TeO}_{2}$-PbO Glass. Journal of Applied Physics, 102, Article ID: 043505. http://dx.doi.org/10.1063/1.2769788

[9] Weber, M.J. (1982) Hand Book of Laser Science and Technology. Vol. 1, CRC, Boca Raton.

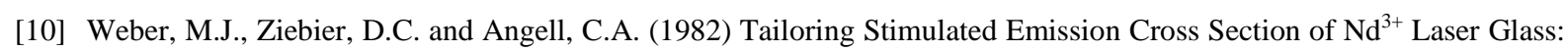
Observation of Large Cross Section for $\mathrm{BiCl}_{3}$ Glasses. Journal of Applied Physics, 53, 4344. http://dx.doi.org/10.1063/1.331214 
[11] Reisfeld, R. (1985) Luminescence and Predication of Transition Probabilities for Solar Energy and Lasers. Journal of the Less Common Metals, 112, 9-18.

[12] Hormadaly, J. and Reisfeld, R. (1979) Intensity Parameters and Laser Analysis of $\mathrm{Pr}^{3+}$ and $\mathrm{Dy}^{3+}$ in Oxide Glasses. Journal of Non-Crystalline Solids, 30, 337-348.

[13] Lakashman, S.V.J. and Kumar, A.S. (1986) Evaluation of Spectroscopic Parameters for $\operatorname{Pr}^{3+}$ Ion in Potassium Zinc Sulphate Glass. Journal of Non-Crystalline Solids, 85, 162-169. http://dx.doi.org/10.1016/0022-3093(86)90088-8

[14] Sharma, Y.K., Mathur, S.C., Dube, D.C. and Tandon, S.P. (1996) Electrical and Optical Band Gap Studies in Neodymium Borophosphate Glasses. Journal of Materials Science, 15, 1054-1056. http://dx.doi.org/10.1007/bf00274904

[15] Sharma, Y.K., Bishnoi, N.B., Surana, S.S.L. and Tandon, S.P. (1992) Spectral Studies of $\mathrm{Pr}^{3+}, \mathrm{Sm}^{3+}$ and $\mathrm{Ho}^{3+} \mathrm{Ions}$ in Sodium Barium Borate Glass. Journal of Pure and Applied Physics, 4, 200-211.

[16] Tandon, S.P., Bishnoi, N.B., Sharma, Y.K. and Surana, S.S.L. (1995) Dependence of Fluorescence Spectra of $\mathrm{Pr}^{3+}$ Doped Chlorophosphate Glasses on Doping Concentration. Journal of Physics, 11, 93-97.

[17] Bhatia, B., Parihar, V., Singh, S. and Verma, A.S. (2013) Spectroscopic Properties of $\mathrm{P}^{\mathrm{r} 3+}$ in Lithium Bismuth Borate Glasses. American Journal of Condensed Matter Physics, 3, 80-88.

[18] Saisudha, M.B., Koteswara, K.S.R., Bhat, H.L. and Ramakrishna, J. (1996) The Fluorescence of Nd ${ }^{3+}$ in Lead Borate and Bismuth Borate Glasses with Large Stimulated Emission Cross Section. Journal of Applied Physics, 80, 4845. http://dx.doi.org/10.1063/1.363520

[19] Wong, E.J. (1963) Configuration Interaction of the $\operatorname{Pr}^{3+}$ Ion. The Journal of Chemical Physics, 38, 976-978. http://dx.doi.org/10.1063/1.1733794

[20] Wong, E.J. (1961) Tayler Series Expansion of the Intermediate Coupling Energy Levels of $\mathrm{Nd}^{3+}$ and $\mathrm{Er}^{3+}$. The Journal of Chemical Physics, 35, 544-546. http://dx.doi.org/10.1063/1.1731965

[21] Gorller-Walrand, C. and Binnemans, K. (1988) Spectral Intensities of f-f Transition. In: Gshneidner Jr., K.A. and Eyring, L., Eds., Handbook on the Physics and Chemistry of Rare Earths, Vol. 25, Chap. 167, North-Holland, Amsterdam, 101-264.

[22] Sharma, Y.K., Surana, S.S.L. and Singh, R.K. (2009) Spectroscopic Investigations and Luminescence Spectra of Sm ${ }^{3+}$ Doped Soda Lime Silicate Glasses. Journal of Rare Earths, 27, 773-780. http://dx.doi.org/10.1016/S1002-0721(08)60333-6

[23] Judd, B.R. (1962) Optical Absorption Intensities of Rare Earth Ions. Physical Review, 127, 750-761. http://dx.doi.org/10.1103/PhysRev.127.750

[24] Ofelt, G.S. (1962) Intensities of Crystal Spectra of Rare Earth Ions. The Journal of Chemical Physics, 37, 511. http://dx.doi.org/10.1063/1.1701366

[25] Goublen, C.H. (1964) Methods of Statistical Analysis. Asian Publishing House, Bombay, Chap. 8, 138.

[26] Babu, P. and Jayasankar, C.K. (2001) Spectroscopy of $\operatorname{Pr}^{3+}$ Ions in Lithium Borate and Lithium Fluoroborate Glasses. Physica B: Condensed Matter, 301, 326-340. http://dx.doi.org/10.1016/S0921-4526(01)00239-3

[27] Sinha, S.P. (1996) Complexes of the Rare Earths. Pergamon Press, Oxford.

[28] Pal, I., Agarwal, A., Sanghi, S. and Aggarwal, M.P. (2011) Structural, Absorption and Fluorescence Spectral Analysis of $\mathrm{Pr}^{3+}$ Ions Doped Zinc Bismuth Borate Glasses. Journal of Alloys and Compounds, 509, 7625-7631. http://dx.doi.org/10.1016/j.jallcom.2011.04.114

[29] Sharma, Y.K. (1991) Spectral and Electoral Properties of Lanthanide Ions in Different Environment. PhD Thesis, University of Jodhpur, Jodhpur.

[30] Dieke, G.H. (1968) Spectra and Energy Levels of Rare Earth Ions in Crystals. InterScience, Johan Wiley and Sons, New York.

[31] Weber, M.J. (1983) Recent Development in Laser Glasses. Proceedings of the International Conference on Lasers, New Orleans, 55-63. 